\title{
Hypoxia in cartilage: HIF-1 $\alpha$ is essential for chondrocyte growth arrest and survival
}

\author{
Ernestina Schipani, ${ }^{1}$ Heather E. Ryan, ${ }^{2}$ Susanna Didrickson, ${ }^{2}$ Tatsuya Kobayashi, ${ }^{1}$ Melissa Knight, ${ }^{1}$ \\ and Randall S. Johnson ${ }^{2,3}$ \\ ${ }^{1}$ Endocrine Unit, Massachusetts General Hospital and Harvard Medical School, Boston, Massachusetts 02114, USA; \\ ${ }^{2}$ Molecular Biology Section, Division of Biology, University of California, San Diego, La Jolla, California 92093, USA
}

\begin{abstract}
Breakdown or absence of vascular oxygen delivery is a hallmark of many common human diseases, including cancer, myocardial infarction, and stroke. The chief mediator of hypoxic response in mammalian tissues is the transcription factor hypoxia-inducible factor 1 (HIF-1), and its oxygen-sensitive component HIF-1 $\alpha$. A key question surrounding HIF-1 $\alpha$ and the hypoxic response is the role of this transcription factor in cells removed from a functional vascular bed; in this regard there is evidence indicating that it can act as either a survival factor or induce growth arrest and apoptosis. To study more closely how HIF-1 $\alpha$ functions in hypoxia in vivo, we used tissue-specific targeting to delete $\mathrm{HIF-1 \alpha}$ in an avascular tissue: the cartilaginous growth plate of developing bone. We show here the first evidence that the developmental growth plate in mammals is hypoxic, and that this hypoxia occurs in its interior rather than at its periphery. As a result of this developmental hypoxia, cells that lack HIF-1 $\alpha$ in the interior of the growth plate die. This is coupled to decreased expression of the CDK inhibitor p57, and increased levels of BrdU incorporation in HIF-1 $\alpha$ null growth plates, indicating defects in HIF-1 $\alpha$-regulated growth arrest occurs in these animals. Furthermore, we find that VEGF expression in the growth plate is regulated through both HIF-1 $\alpha$-dependent and -independent mechanisms. In particular, we provide evidence that VEGF expression is up-regulated in a HIF-1 $\alpha$-independent manner in chondrocytes surrounding areas of cell death, and this in turn induces ectopic angiogenesis. Altogether, our findings have important implications for the role of hypoxic response and HIF-1 $\alpha$ in development, and in cell survival in tissues challenged by interruption of vascular flow; they also illustrate the complexities of HIF-1 $\alpha$ response in vivo, and they provide new insights into mechanisms of growth plate development.
\end{abstract}

[Key Words: Hypoxia; cartilage]

Received August 3, 2001; revised version accepted September 10, 2001.

E. Newton Harvey noted in 1928 that the partial pressure of oxygen needed for survival of cells in the interior of a sphere is a function of the square of the radius of the tissue: $\mathrm{F}_{\mathrm{O} 2}=\mathrm{V}_{\mathrm{O} 2} \mathrm{r}^{2} / 6 \mathrm{~K}$ (where $\mathrm{F}_{\mathrm{O} 2}$ equals the partial pressure of oxygen at the surface, $\mathrm{V}_{\mathrm{O} 2}$ equals oxygen consumption of the tissue, and $\mathrm{K}$ is the diffusion constant) (Harvey 1928; Schmidt-Nielsen 1990). Physiologically, this dictates that survival of any group of cells is rapidly limited by their distance from a source of oxygen. An important aspect of survival of cells during hypoxic challenge is the ability of the cells to transiently or chronically tolerate lowered oxygen levels via adaptive responses. Adaptations to hypoxia include shifting metabolic catabolysis to an anaerobic/glycolytic mode, and inducing neovascularization via expression of angiogenic factors (Semenza 2000a; Seagroves et al. 2001). In par-

${ }^{3}$ Corresponding author.

E-MAIL rsjohnson@ucsd.edu; FAX (858) 534-5831.

Article and publication are at http://www.genesdev.org/cgi/doi/10.1101/ gad. 934301 . ticular, as tissues grow and exceed the capacity of the local vasculature to deliver oxygen, these adaptations are likely critical for successful tissue expansion. This response is exploited by malignant tumors as well, as it allows the expansion of the vascular bed of the tumor via the hypoxia-induced release of angiogenic factors (Semenza 2000b).

The transcription factor hypoxia-inducible factor 1 (HIF-1) appears to be one of the major regulators of the hypoxic response. HIF-1 controls hypoxic expression of erythropoietin, as well as the expression of genes with metabolic functions such as glucose transport and metabolism, and angiogenic factors like vascular endothelial growth factor (VEGF) (Semenza 1999). HIF-1 is a heterodimer of the PAS subfamily of basic-helix-loop-helix (bHLH) transcription factors, and it consists of the subunit HIF-1 $\alpha$, the hypoxically responsive component of the complex, and the constitutively expressed HIF-1 $\beta$ subunit or ARNT (Semenza 1999). Two other hypoxiaresponsive homologs of the HIF-1 $\alpha$ gene have been cloned recently, yet there appears to be little redundancy 
in hypoxic response (Semenza 1999). Mice that lack HIF$1 \alpha$ as a result of homologous recombination $\left(H I F-1 \alpha^{-/-}\right.$ die around day 9 of gestation (Iyer et al. 1998; Ryan et al. 1998). Due to the early lethality of $H I F-1 \alpha^{-/-}$mice, most functional studies to this point have been conducted in cell lines or ES-cell derived tumors transplanted into nude mice (Carmeliet et al. 1998; Ryan et al. 1998, 2000).

The HIF-1 complex is ubiquitous (Weiner et al. 1996; Jain et al. 1998), and presence of this complex in growth plate chondrocytes has been documented recently (Rajpurohit et al. 1996). Growth plate chondrocytes go through well-ordered and controlled phases of cell proliferation, differentiation, and apoptosis (Erlebacher et al. 1995; Harper and Klagsbrun 1999). Round proliferative chondrocytes that synthesize collagen type II protein form a columnar layer, and then differentiate into postmitotic hypertrophic cells that express predominantly collagen type $\mathrm{X}$ and produce VEGF. Differentiation is followed by death of hypertrophic chondrocytes, blood vessel invasion, and replacement of the cartilage matrix with a trabecular bone matrix. The growth plate is a constitutively avascular tissue; therefore, it has been assumed that the low oxygen partial pressure in the chondrocytic growth plate imposes energetic limitations on the cells as they evolve from a proliferative to a terminally differentiated state (Rajpurohit et al. 1996). How- ever, no data are available that directly address this issue.

We speculated that HIF- $1 \alpha$ could play a role in chondrocyte adaptation to low oxygen tension and that the growth plate could be a useful and informative model to investigate the mechanism of action of HIF-1 $\alpha$. To characterize the need for hypoxic response in tissues where vascular function is interrupted and oxygen delivery becomes limited, we targeted deletion of the HIF-1 $\alpha$ gene to the cartilaginous growth plate.

\section{Results}

The chondrocytic growth plate is hypoxic

To ascertain the presence and degree of hypoxia in mammalian fetal cartilage, we injected a marker for bioreductive activity into pregnant female mice at embryonic day 15.5 (E15.5). This marker, the nitroimidazole EF5, allowed us to study distribution of the molecule in the fetal growth plate via a rhodamine-coupled anti-EF5 antibody (Fig. 1a-d) (Lord et al. 1993; Lee et al. 1996a). Immunohistochemical analysis showed that the fetal chondrocytic growth plate bound EF5 exclusively; no binding was detected in surrounding muscle and bone (Fig. 1d). Furthermore, the most highly hypoxic chondro-
Figure 1. Detection of hypoxia and HIF-1 $\alpha$ protein in wild-type growth plate. $(a, b)$ Brightfield and immunofluorescence detection of EF-5 in proximal epiphysis of wild-type E15.5 tibia. (c) Overlay of $a$ and $b$. (d) Immunofluorescence detection of EF-5 in E15.5 tibia and surrounding muscular tissue. (e) HIF-1 $\alpha$ protein detection in the proximal epiphysis of wild-type E15.5 fetal tibia by immunoperoxidase analysis; the arrows indicate positively stained nuclei; for purposes of orientation, the border of the growth plate is drawn.

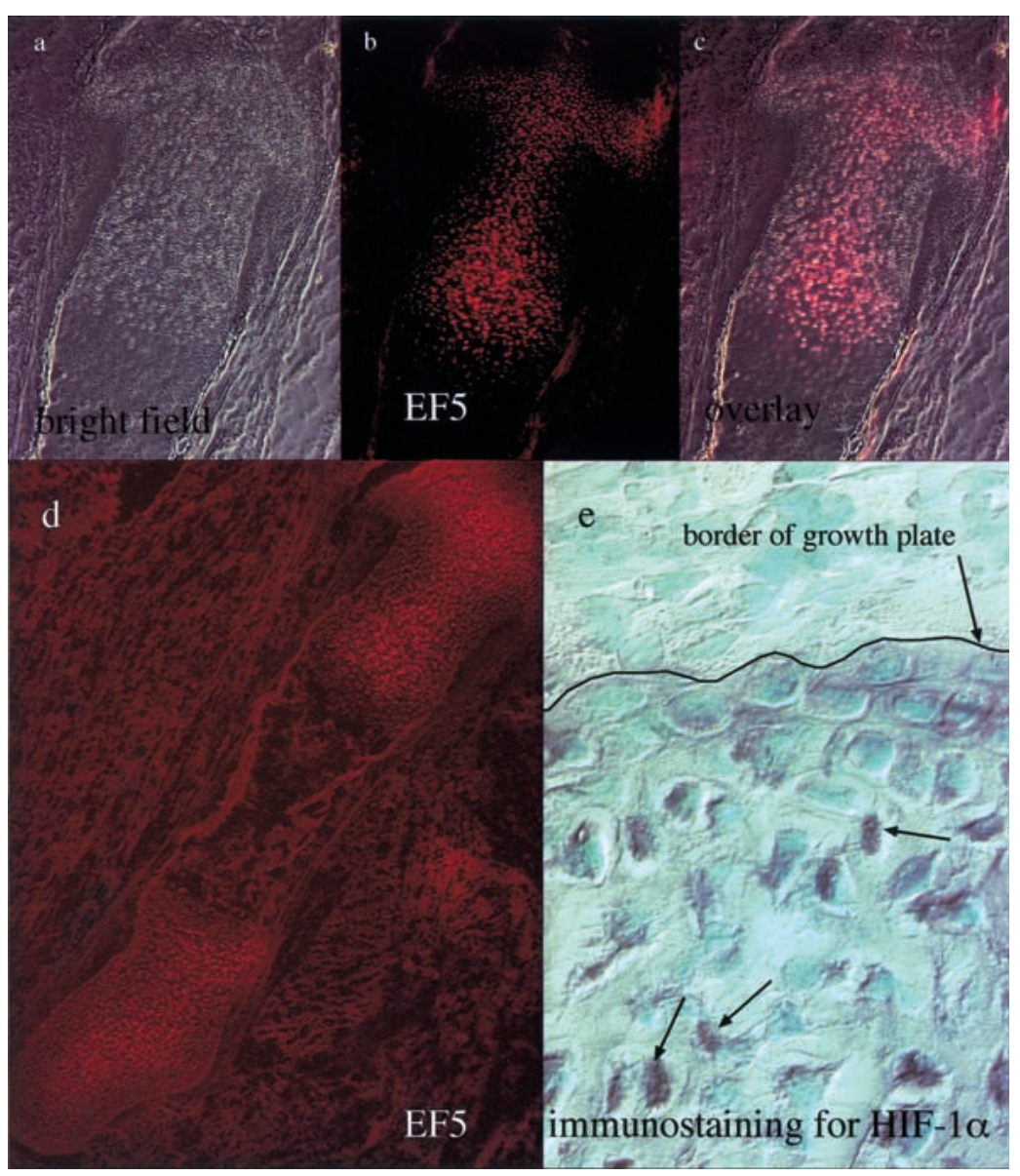


cytes were located in the round proliferative layer near the joint space, in the center of the columnar proliferative layer and in the upper portion of the hypertrophic zone (Fig. 1a-c). A developmental analysis of EF5 binding from E14.5 to E18.5 confirmed that the localization of this marker in the growth plate was similar throughout gestation (data not shown). These data documented for the first time the presence of a gradient of oxygenation, not only from the proliferative to the hypertrophic zone, but also from the outer to the inner region of the fetal growth plate. The hypoxic condition of the early hypertrophic chondrocytes, despite their proximity to the blood vessels of the primary spongiosa, could be explained by the high diffusion coefficient in the mineralized hypertrophic layer; this may result in a significant barrier to the diffusion of oxygen and nutrients from the metaphysis.

Consistent with the determination of hypoxia in this tissue, we found that immunohistologically detectable expression of HIF- $1 \alpha$ also occurred in the interior of the developing growth plate (Fig. 1e).

\section{Generation of mice lacking HIF-1 $\alpha$ in growth} plate chondrocytes

Because of the early lethality of mice nullizygous for

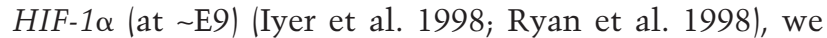

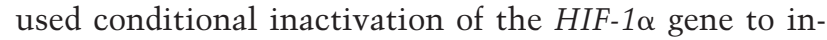

vestigate the role of this transcription factor in chondrocytes. For this purpose, two independent Cre transgenic lines were generated in which P1 phage Cre integrase was placed under the transcriptional control of the rat collagen $2 a 1$ gene promoter and enhancer sequences (Yamada et al. 1990) (Fig. 2a). To examine sites of Cre activity, both Cre transgenic lines were crossed with lacZreporter animals in which $\beta$-galactosidase expression is activated following Cre-mediated excision of a stop codon (Soriano 1999). Whole mount $\beta$-galactosidase staining analysis conducted on E15.5 double transgenic fetuses showed a staining pattern consistent with Crespecific activity in growth plate chondrocytes in both transgenic lines (Fig. 2b,c). Analysis of Cre expression by in situ hybridization confirmed that expression of the transgene was restricted to cartilage (Fig. 2d).

$\mathrm{F}_{1}$ Cre offspring (collicre) from both transgenic lines were bred with animals heterozygous for both the floxed and the null $H I F-1 \alpha$ alleles $\left(H I F-1 \alpha^{+\mathrm{f} /-}\right)$, respectively (Ryan et al. 1998, 2000). Newborn HIF-1 $\alpha^{+\mathrm{f} /-}$; collIcre and $H I F-1 \alpha^{+\mathrm{f} / \mathrm{+}}$; colIIcre null mice, generated after appropriate mating, were smaller than control littermates with a characteristic shortening of the forelimbs and the hindlimbs (Fig. 2e), and always died within a few hours of birth. No premature death occurred during fetal development, as null embryos could be collected at different dates of embryonic development with the expected Mendelian frequency (Table 1).

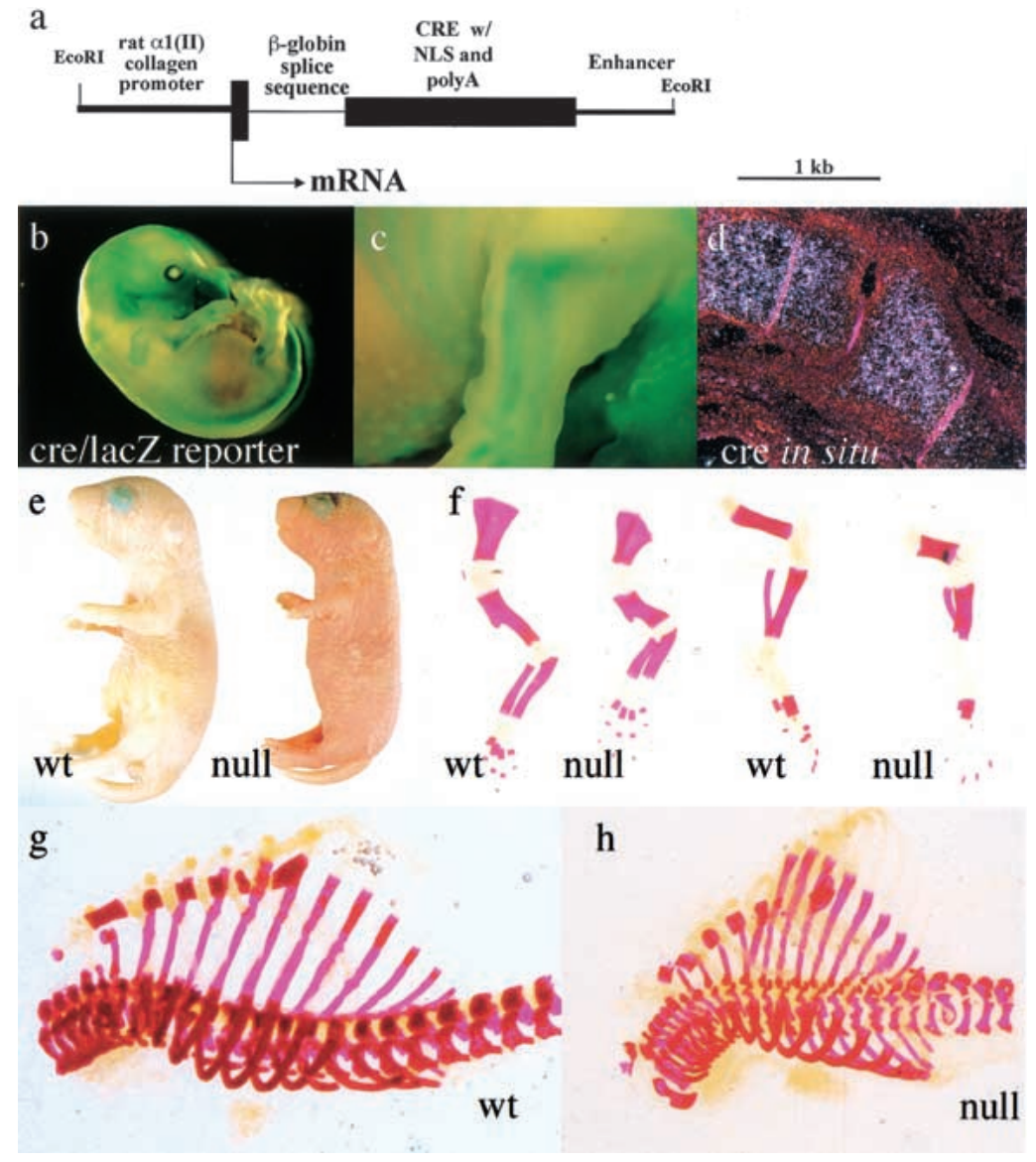

Figure 2. Generation of mutant animals lacking $H I F-1 \alpha$ in growth plate chondrocytes. (a) Schematic representation of the colliCre transgene. $(b, c)$ Whole-mount $\beta$-galactosidase staining of E15.5 embryo. (d) in situ hybridization analysis with antisense Cre riboprobe on histological sections of wild-type hindlimb from E15.5 embryo. (e) Picture of newborn wild-type ( left) and null mouse littermates (right). $(f-h)$ Whole skeleton Alizarin Red S staining; newborn wild-type (left) and mutant (right) forelimbs (left) and hindlimbs (right) are shown in $f_{;}$newborn wild-type rib cage is shown in $g$; newborn null rib cage is shown in $h$. 
Schipani et al.

Table 1. Animals recovered

\begin{tabular}{lcr}
\hline & Total & Null \\
\hline Newborn & 85 & 11 \\
E18.5 & 30 & 6 \\
E15.5 & 63 & 6 \\
E14.5 & 29 & 3 \\
\hline
\end{tabular}

Expected null 1:8.

The lack of HIF-1 $\alpha$ in chondrocytes causes gross skeletal malformation

Identical phenotypes were observed with both of the two transgenic collIcre lines in HIF-1 $\alpha^{-\mathrm{f} /-} /$ colIICre and HIF$1 \alpha^{-\mathrm{f} /-\mathrm{f}} /$ colIIcre backgrounds; HIF-1 $\alpha^{+\mathrm{f} /-} /$ colIIcre, HIF$1 \alpha^{+\mathrm{f} / \mathrm{f}}$, and both strains of collicre transgenic animals, respectively, were indistinguishable from wild-type mice. The intact skeletons of the null mice, stained with Alizarin Red S, did not show significant differences in the degree and pattern of mineralization of the different skeletal elements (Fig. 2f-h; data not shown). However, mutant hindlimbs and forelimbs were shorter and de- formed in comparison to those of control littermates (Fig. 2f). Furthermore, the mutant rib cages were also abnormally wider and misshapen (Fig. 2g,h). No gross abnormalities could be detected in other organs and tissues, including the heart (data not shown).

\section{Tracheal abnormalities in mice lacking HIF-1a} contribute to perinatal death

To determine the cause of perinatal lethality in the conditionally targeted mice, we determined whether cartilaginous elements other than the ones involved in endochondral bone development could be affected by the lack of HIF-1 $\alpha$. For this purpose, we studied the trachea in mutant and wild-type newborn animals. Histological analysis revealed that in the mutant trachea chondrocyte morphology and organization was altered, and that the tracheal epithelium was partially collapsed, probably as a result of an abnormal growth of the cartilaginous ring and weakening during initial attempts to breathe postnatally (Fig. 3e-i). It is likely that this partial collapse of the tracheal structure contributes significantly to the
Figure 3. Histological analysis of long bone growth plates and trachea in wild-type and null animals. $(a, b) \mathrm{H} \& \mathrm{E}$ staining of wild-type and mutant newborn tibias; portions of the distal epiphysis of the femur and of fibula and calcaneus are also shown. $(c, d) \mathrm{H} \& \mathrm{E}$ staining of distal epiphysis of newborn wild-type and null tibias (higher power of $a$ and $b$, respectively). (e-i) H\&E staining of wild-type and null tracheas. $g$ and $i$ are higher power of $f_{i} h$ is higher power of $e$.

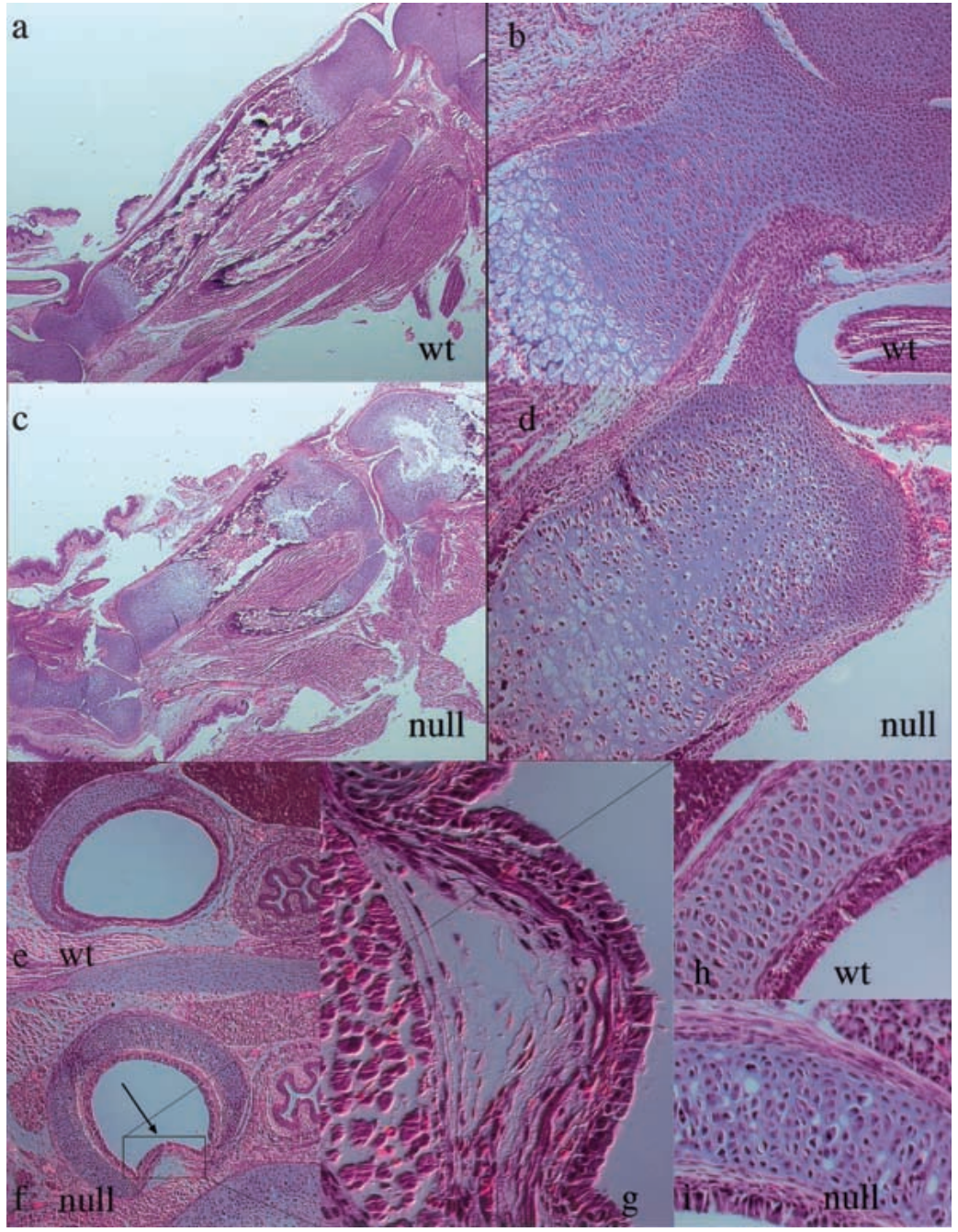


early lethality of the mutant animals; further evidence for this comes from the lack of fully expanded lungs in mutants analyzed postnatally (data not shown).

\section{Loss of HIF-1 $\alpha$ results in cell death in the center of cartilaginous elements}

The long bones of newborn null animals were significantly shorter than controls (Fig. 3a,c). The growth plates were misshapen and wider, and the organization of growth plate chondrocytes was noticeably disrupted. In particular, the area in the center of both the proliferative columnar layer and the upper hypertrophic zone was either remarkably hypocellular or otherwise occupied by abnormal cellular elements with pycnotic nuclei (Fig. $3 \mathrm{~b}, \mathrm{~d})$. Furthermore, the border between the chondrocytic hypertrophic zone and the bony primary spongiosa was irregular and disorganized (Fig. 3a,c). This striking histological phenotype was first detected at E14.5 and was already quite severe at E15.5 (data not shown). It was consistently most evident in the core of the mutant cartilaginous element, although within a few microns from the proximal surface of the mutant specimens there were few if any cellular abnormalities.

The highly specific spatial localization of the mutant phenotype to the center of the cartilaginous elements was also seen in the histological analysis of the null rib cage (Fig. 4a-d). Serial sections of sternebrae of control newborn animals consistently showed hypertrophic differentiation of chondrocytes, blood vessel invasion, primary spongiosa, and bone marrow cavity formation (Fig. 4a). Conversely, no elements with a clear cellular morphology could be identified in the center of the mutant sternebrae (Fig. 4b). Similar findings could also be observed at the chondrosternal junction of the mutant ribs (Fig. 4c,d); these are skeletal segments in which chondrocytes normally do not undergo hypertrophic differentiation and apoptosis and are not normally replaced by bone cells. Interestingly, the lack of HIF-1 $\alpha$ in chondrocytes had not affected either the development of the large intercostal vessels (Fig. 4e,f) or the capillary density of the perichondrium surrounding the ribs (Fig. 4g,h). Taken together, these data strongly suggested that the severe cellular abnormalities in the center of the mutant

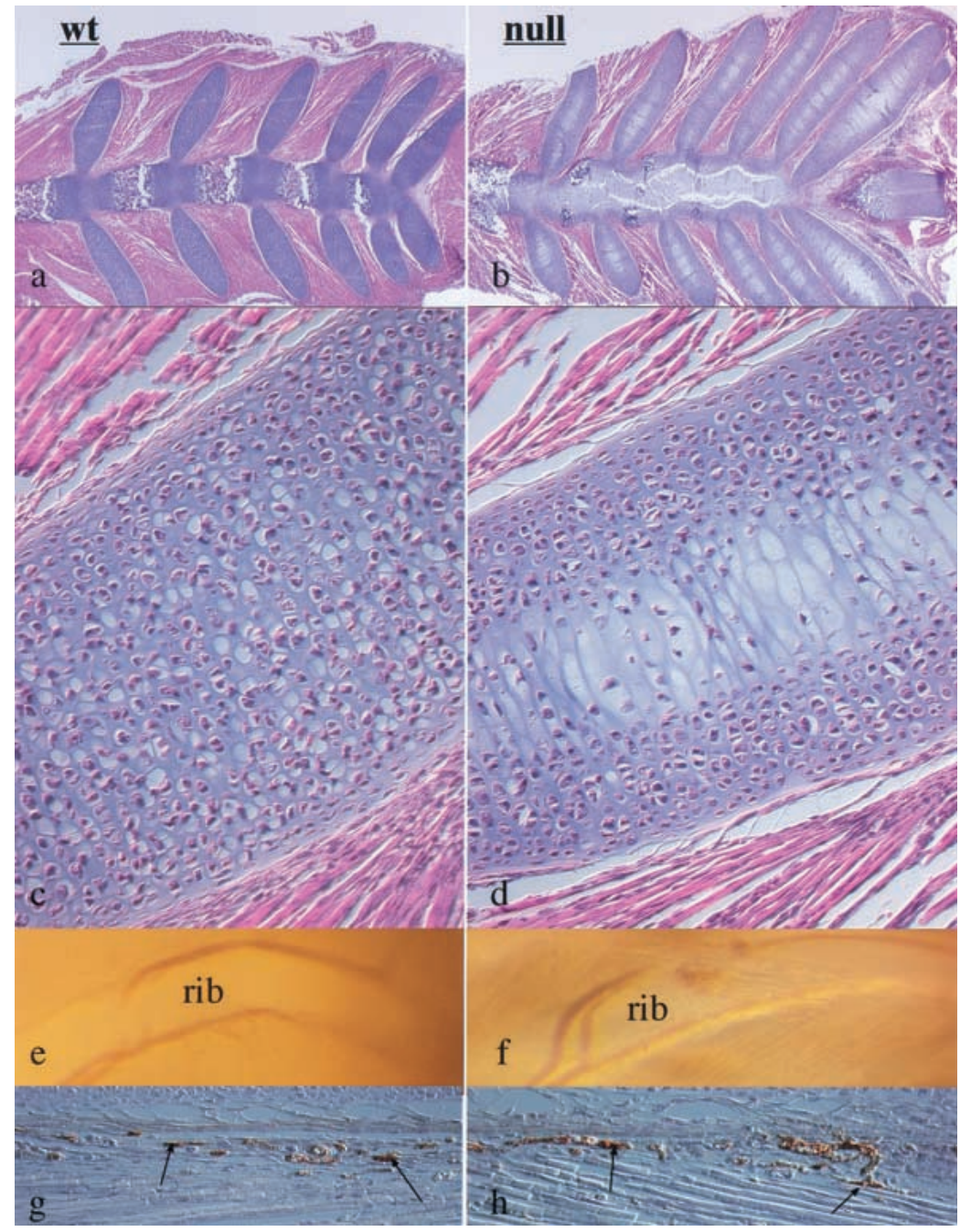

Figure 4. Analysis of rib cage and intercostal blood vessels in wild-type and null animals. $(a, b)$ H\&E staining of wild-type and mutant newborn sterna and ribs at their chondrosternal junction. $(c, d) \mathrm{H} \& \mathrm{E}$ staining of newborn wild-type and mutant ribs (higher power of $a$ and $b$, respectively). $(e, f)$ Brightfield pictures of wild-type and mutant rib cages adjacent to the chondrosternal junction; the intercostal blood vessels that surround the ribs are clearly evident in both wild-type and mutant specimens. $(g, h)$ Immunostaining for von Willebrand factor in the perichondrium surrounding wild-type and mutant ribs in a region adjacent to the chondrosternal junction; the arrows indicate positively stained capillaries. 
sternum and ribs had occurred despite the presence of normal vascular development in the periphery of these cartilaginous elements.

Loss of HIF-1 $\alpha$ causes cell death without concomitant hypertrophic differentiation

We then performed in situ hybridization analysis and TUNEL assays on histological sections of hindlimbs from wild-type and null animals. The presence of cells expressing the chondrocyte markers collagen type II and collagen type $X$ at the periphery of the mutant growth plate (Fig. 5a,b), as detected by in situ hybridization, indicated that the lack of HIF-1 $\alpha$ had not severely altered the process of chondrocyte differentiation per se. However, the absence of both collagen type II and type $X$ mRNA expression (Fig. 5a,b), and the presence of numerous TUNEL positive cells (Fig. $5 \mathrm{~d}$ ) in the central portion of both the proliferative and the upper hypertrophic zones in the mutant growth plate provided clear evidence that chondrocytes in the core of the cartilaginous element of the newborn mutant limbs were undergoing massive cell death and that, therefore, HIF- $1 \alpha$ was required for survival of hypoxic chondrocytes. Identical results were provided by in situ hybridization analysis of sections of hindlimbs from wild-type and null embryos at different stages of embryonic development (data not shown). Interestingly, no ectopic expression of collagen type $X$ mRNA was detected in the mutant growth plate at any time point of fetal development and/or at birth (Fig. 5b; data not shown). This shows that, unlike what is seen during wild-type chondrocyte differentiation, in the null growth plate, hypertrophic differentiation was not a required step prior to cell death.

\section{Mutant animals exhibit a retarded chondrocyte hypertrophy in the sternum}

Consistent with the data obtained by analysis of the limbs and in contrast to the wild-type phenotype, no collagen type $I I$ and/or type $X$ mRNA expression was observed in the center of the newborn mutant sternum and ribs at their chondrosternal junction (Fig. 5a,b). Endochondral bone development occurring in the sternum

Figure 5. Evidence of massive cell death and decreased expression of p57 mRNA in mutant growth plate chondrocytes. $(a)$ in situ hybridization analysis with collagen type II cRNA on histological sections from newborn wild-type and mutant tibias and rib cages, respectively; the darkfields of the proximal epiphyses and of the rib cages for both wild-type and mutant specimens are shown. (b) In situ hybridization analysis with collagen type $X$ cRNA on histological sections from E15.5 wild-type and null tibias and newborn rib cages, respectively; the darkfields of the proximal epiphyses and of the rib cages for both wildtype and mutant specimens are shown. (c) In situ hybridization analysis with p57 cRNA on histological sections from E18.5 wild-type and mutant tibias; the darkfields for both wild-type and mutant specimens are shown. (d) Fluorescence detection (FITC) of TUNEL positive cells in the proximal epiphyses of wild-type and mutant newborn tibias; in comparison to the wild-type specimen, numerous TUNEL-positive cells are clearly evident in the mutant.
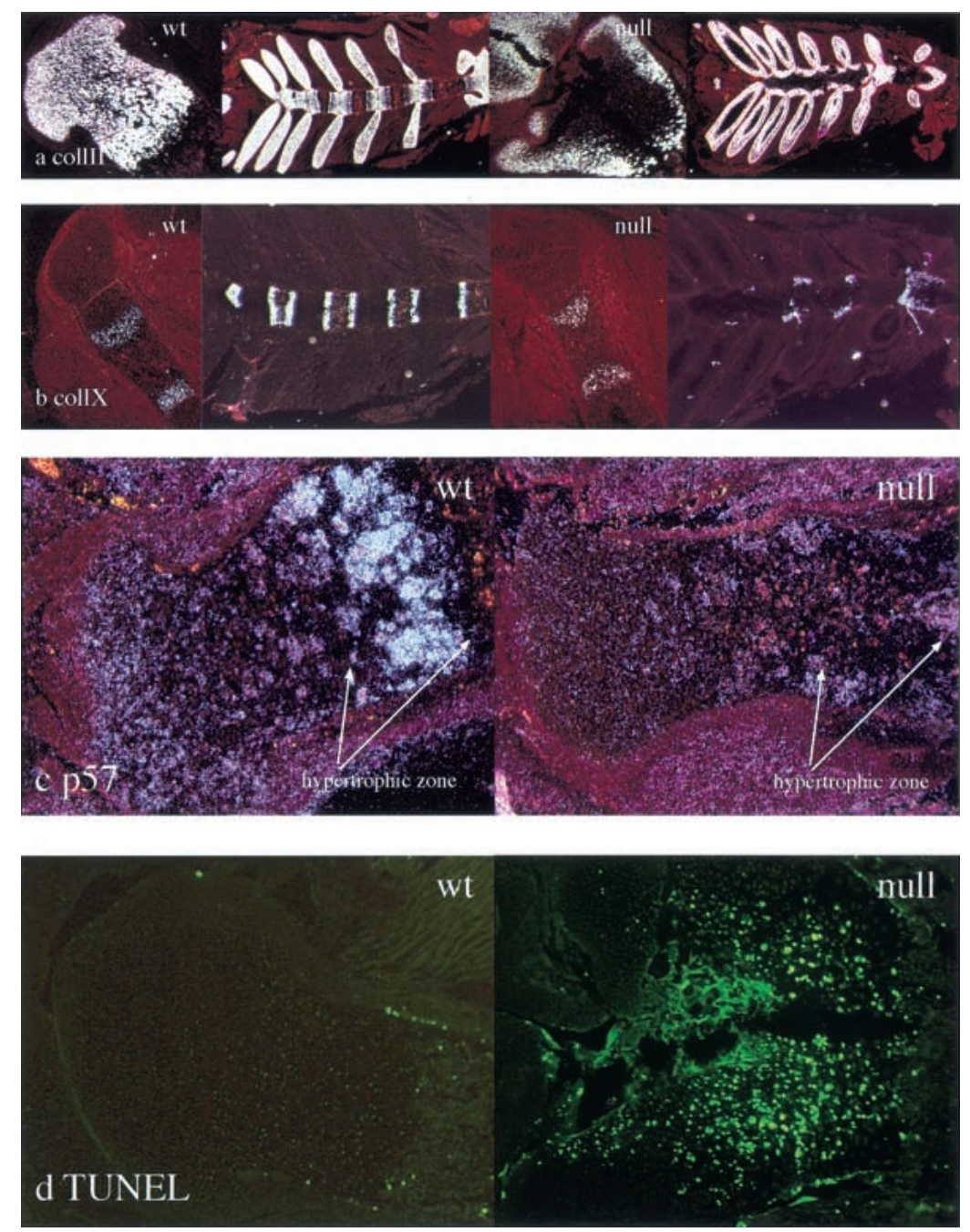
follows a specific temporal-spatial axis; chondrocytes in the sternebrae near the manubrium undergo hypertrophic differentiation earlier than chondrocytes in the sternebrae near the xyphoid process. Interestingly, in the newborn wild-type sternum hypertrophic differentiation was present consistently in each sternebrae (Fig. 5b). Conversely, in the null specimens chondrocytes in the proximity of the xyphoid process express exclusively collagen type $I I$, and no collagen type $X$ mRNA could be detected by in situ hybridization analysis of these cells (Fig. 5a,b). These data provide evidence that the lack of HIF- $1 \alpha$ results not only in a massive cell death in the center of the cartilaginous elements, but also in a subtle delay in the process of chondrocyte differentiation at its periphery. Likely caused by the unique anatomical structure of the sternum, this subtle delay was more easily detectable in the sternum than in the long bones.

Loss of HIF-1 $\alpha$ is correlated with a loss of p57 expression and a decrease in chondrocyte growth arrest

To better understand the role that loss of HIF-1 $\alpha$ was playing in cell death in the absence of hypertrophic dif- ferentiation, we analyzed the expression of a key regulator of chondrocyte cell growth arrest, p57kip2; this CDK inhibitor is expressed in the cartilage (Yan et al. 1997; Zhang et al. 1997; Nagahama et al. 2001). Loss of this molecule causes an inability of the growth plate to initiate, first growth arrest, and then ultimately both differentiation and apoptosis (Yan et al. 1997; Zhang et al. 1997; Nagahama et al. 2001). Strikingly, this molecule was missing from the hypertrophic regions of HIF-1 $\alpha$ null chondrocytic growth plates (Fig. 5c); this indicates that one possible source of altered cell viability is an inability to increase expression of $p 57$ and induce growth arrest in a coordinated fashion.

To determine whether this defect in p57 expression correlated with altered rates of growth arrest in the chondrocytes in vivo, we performed BrdU incorporation analysis in E14.5 and E15.5 hindlimbs from both mutant and wild-type embryos. BrdU incorporation was significantly increased in comparison to wild type at the periphery of the mutant growth plate, in regions where no dead cells could be observed by either histological or in situ hybridization criteria (Fig. 6c-e). Consistent with the previously described central cell death phenotype, no

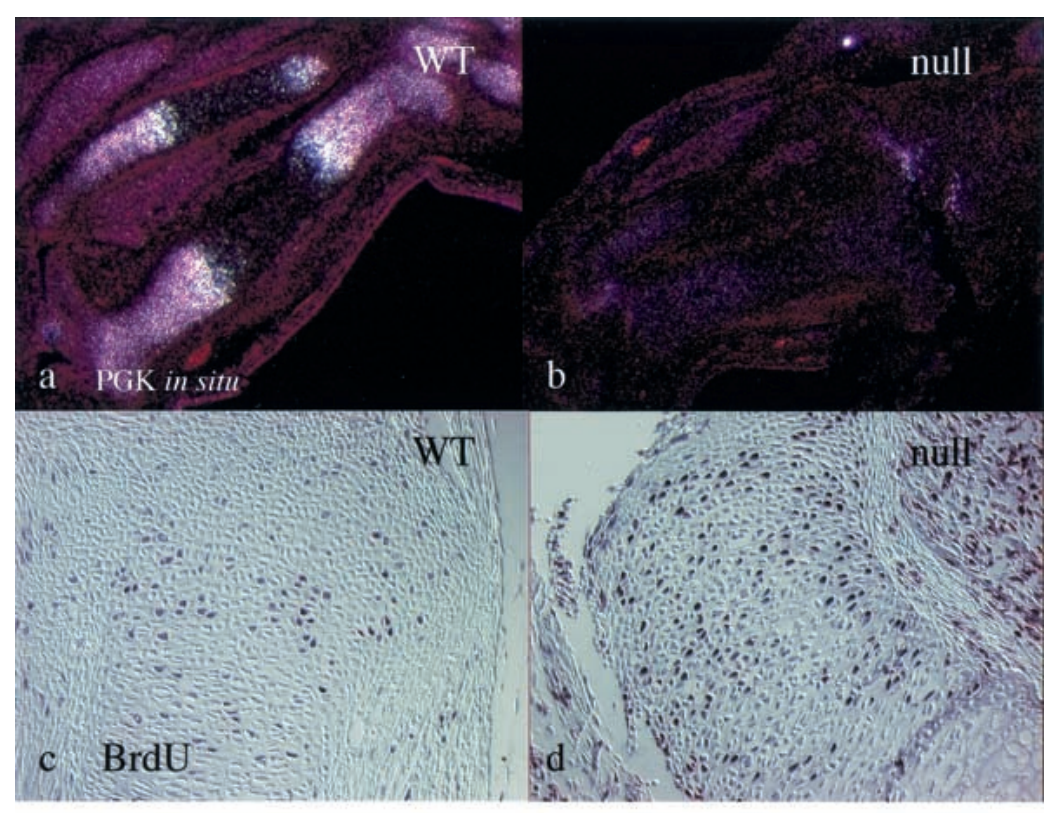

e

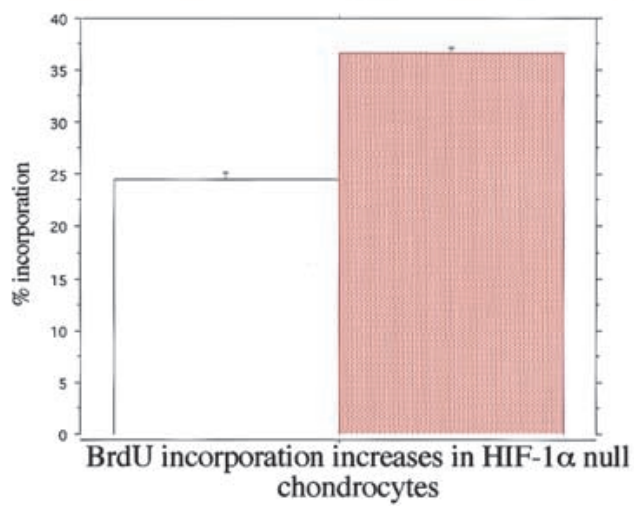

Figure 6. Evidence for loss of $P G K$ expression and increased proliferation rate in mutant growth plate chondrocytes. $(a, b)$ In situ hybridization analysis with $P G K$ cRNA on histological sections from E15.5 wild-type and mutant tibias and fibulas; the darkfields for both wild-type and mutant specimens are shown. $(c, d)$ Detection of BrdU positive cells on histological sections from E15.5 wild-type and mutant tibias, respectively. Sections were counterstained with methyl green. $(e)$ Quantification of BrdU positive cells outside of regions of necrosis, defined as cells more than one cell layer from clearly necrotic regions; percent positive is as a function of total cells counted in the selected region. A significant increase in incorporation in nullizygous chondrocytes is seen. Error bars represent one standard error; counts were done on 10 growth plate regions from the long bones of five independent embryos for each genotype. (Open bar) Wild type (WT); (red bar) Null. 
BrdU incorporation could be detected in the center of the mutant growth plate (Fig. 6d).

Evidence for action of HIF-1 $\alpha$ as a survival factor, and for HIF-1 $\alpha$-dependent and HIF-1 $\alpha$-independent regulation of VEGF expression

We next investigated molecular mechanisms that could mediate action of HIF- $1 \alpha$ as a survival factor in chondrocytes. Two important aspects of hypoxic response mediated by HIF-1 are increased expression of the angiogenic factor VEGF, and increased activity of the glycolytic or anaerobic component of metabolism. This latter is mediated by increased expression of many of the glycolytic enzymes, such as phosphoglycerate-kinase1 (PGK), whose hypoxic up-regulation is completely HIF- $1 \alpha$ dependent (Firth et al. 1994; Semenza et al. 1994; Li et al. 1996; Ryan et al. 1998). We then asked whether cellautonomous mechanisms, such as regulation of cellular metabolism, or non cell-autonomous activity, such as regulation of angiogenesis in the surrounding bone tissue, played a role in mediating the action of HIF-1 $\alpha$ as a survival factor in growth plate chondrocytes. For this purpose, we studied PGK and VEGF mRNA expression in the growth plates of null animals and control littermates, respectively, by in situ hybridization analysis. Because of the severity of the phenotype at birth, in situ hybridization analysis with $P G K$ and VEGF cRNAs was first performed on histological sections from E15.5 wildtype and mutant hindlimbs, and chondrocyte viability was confirmed on adjacent serial sections by chondrocyte markers such as collagen type II and collagen type $X$ cRNAs (data not shown). These results were also confirmed by analysis of histological sections from E18.5 and/or newborn hindlimbs from wild-type and mutant mice (data not shown).

$P G K$ mRNA was expressed throughout the growth plate (Fig. 6a). Furthermore, its levels were significantly higher in upper hypertrophic chondrocytes, which were also the most hypoxic cells in the mouse fetal growth plate, as shown by EF-5 distribution (Fig. 1a-c). Strikingly, $P G K$ mRNA expression was reduced to background levels throughout the HIF-1 $\alpha$ null growth plate (Fig. 6b). Recently we have shown the relationship between HIF- $1 \alpha$-induced expression of PGK and other glycolytic enzymes and metabolic response to hypoxia (Seagroves et al. 2001). Given this, it is likely that there is a significant metabolic deficit in this tissue.

In the growth plate, VEGF is expressed mainly by the late hypertrophic chondrocytes and is thought to play a crucial role in regulating the number of blood vessels of the primary spongiosa and, through this mechanism, the replacement of cartilage by bone (Gerber et al. 1999; Haigh et al. 2000). VEGF mRNA expression was significantly decreased in mutant hypertrophic chondrocytes in comparison to controls (Fig. 7a,b). Consistent with this finding, the mutant primary spongiosa was markedly irregular, as suggested by a patchy distribution of $M M P 9$, a metalloproteinase produced by osteoclast-like cells located at the border between growth plate and primary spongiosa (data not shown).

Interestingly, prolonged exposure to photoemulsion revealed still significant expression of VEGF mRNA in the mutant hypertrophic chondrocytes (Fig. 7c,d). Furthermore, augmented expression of VEGF mRNA around the area of cell death was observed (Fig. 7c,d). This up-regulation of VEGF was likely secondary to the severe changes in the redox status of the chondrocytes surrounding the area of cell death, as demonstrated by their dramatic increase in EF-5 binding (Fig. 7e,f). In addition, it is plausible that it triggered a marked and highly unusual ectopic angiogenesis, clearly noticeable in numerous areas of necrosis in selected null growth plates (Fig. 7g-i).

Taken together, our data suggest that VEGF expression in the growth plate is likely to be regulated through both HIF- $1 \alpha$-dependent and HIF- $1 \alpha$-independent mechanisms, and that this in turn can act to effect ectopic angiogenesis in necrotic cartilaginous regions.

\section{Discussion}

The putative role of HIF- $1 \alpha$ as survival factor has recently become the focus of controversy (Maxwell et al. 1997; Carmeliet et al. 1998; Ryan et al. 1998, 2000; Wood et al. 1998; Kung et al. 2000; Semenza 2000b). Studies conducted in cell lines or in ES cell-derived tumors show that HIF- $1 \alpha$ activity modulates tumor cell growth by regulating both metabolic functions and expression of angiogenic growth factors such as VEGF (Semenza 1999; Kung et al. 2000; Ryan et al. 2000). Despite an initial report indicating that HIF- $1 \alpha$ would act as a negative factor for the growth of ES cell-derived tumors, a considerable amount of in vitro data now support the model that the lack of HIF- $1 \alpha$ retards tumor growth (Ryan et al. 1998, 2000; Wood et al. 1998; Elson et al. 2000; Kung et al. 2000; Ratcliffe et al. 2000). Consistent with this notion, it has been reported that activation of the PI3K/ AKT/FRAP survival pathway stabilizes expression of HIF- $1 \alpha$ protein and its transcriptional activity (Zhong et al. 2000; Zundel et al. 2000).

Our data, which represent the first tissue-specific deletion of hypoxic response via HIF-1 $\alpha$ clearly show for the first time that hypoxic chondrocytes lacking HIF-1 $\alpha$ undergo massive death and that, therefore, HIF-1 $\alpha$ is absolutely critical for survival of hypoxic cells in a fully differentiated tissue.

Interestingly, in the mutant cartilage, cell death took place in the center of both the proliferative and the hypertrophic layers, suggesting that in the absence of HIF$1 \alpha$ hypertrophic differentiation was not a required step for cell death. Consistent with this notion, ectopic hypertrophy, identified on the basis of both morphological and in situ hybridization criteria (i.e., expression of collagen type $X$ mRNA), was never detected in the null growth plate at any time during fetal development, or at birth. Interestingly, the lack of HIF-1 $\alpha$ also caused massive cell death in cartilaginous elements in which chon- 


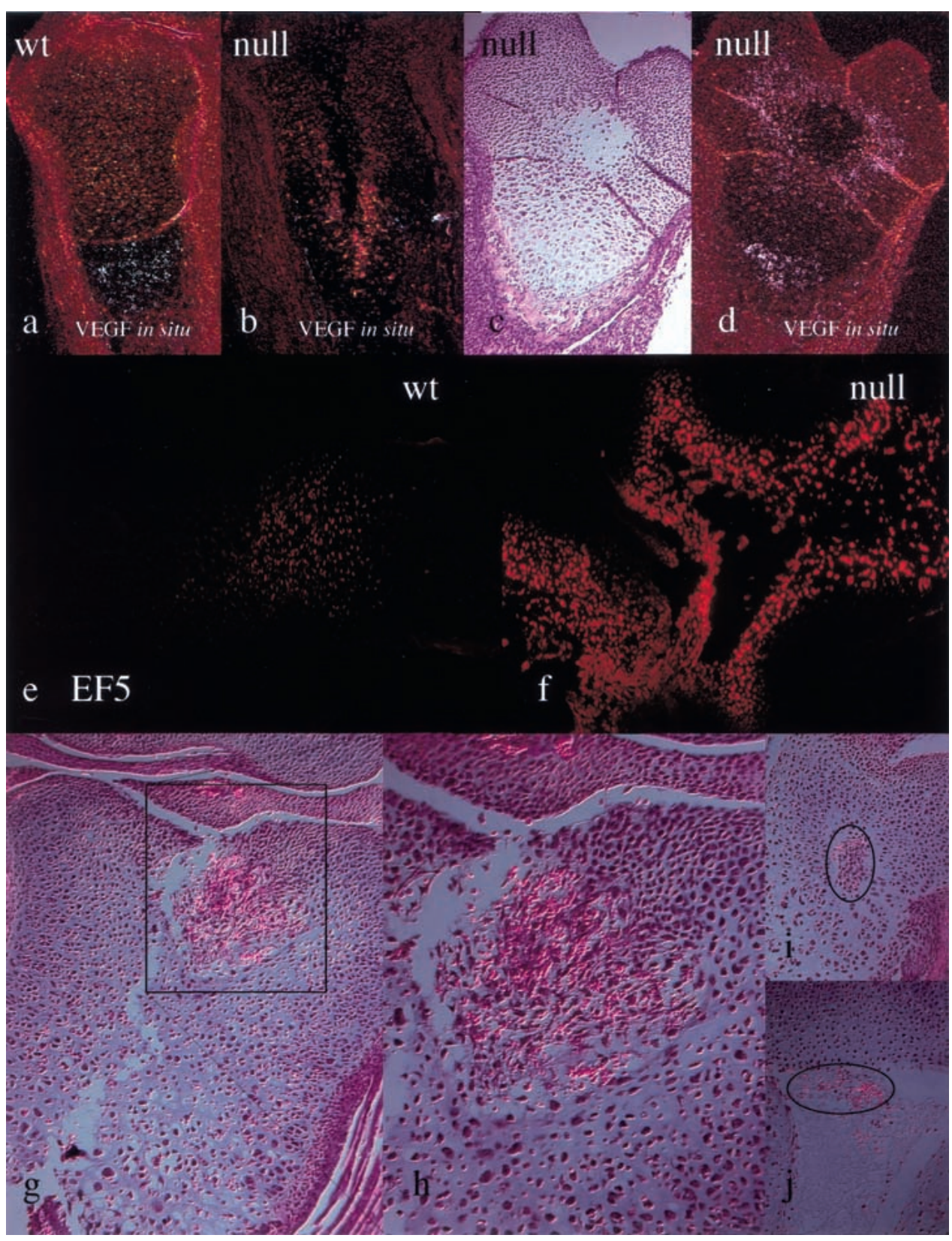

Figure 7. Evidence for HIF- $1 \alpha$-dependent and -independent regulation of VEGF expression, increase of EF-5 binding, and ectopic angiogenesis in the mutant growth plate. $(a, b)$ In situ hybridization analysis with VEGF cRNA on histological sections E15.5 from wild-type and mutant tibias and fibulas; the darkfields for both wild-type and mutant specimens are shown (exposure to photoemulsion $=14 \mathrm{~d}) .(c, d)$ In situ hybridization analysis with VEGF cRNA on histological sections from E15.5 mutant femur; brightfield and darkfield are shown, respectively (exposure to photoemulsion $=24 \mathrm{~d}) .(e, f)$ Immunofluorescence detection of EF-5 in proximal epiphysis of E18.5 wild-type and mutant tibia, respectively. $(g-i) \mathrm{H} \& \mathrm{E}$ staining of histological sections of proximal epiphyses of mutant newborn tibias; square and circles are drawn around areas of ectopic angiogenesis; $h$ is a higher magnification image of $g$.

drocytes do not generally undergo hypertrophic differentiation, such as the chondrosternal junction of the ribs.

HIF- $1 \alpha$ is essential for the "Pasteur effect" in mammalian cells, that is, the increased expression of glycolytic enzymes and a concomitant increased reliance on them for ATP production in hypoxic conditions (Seagroves et al. 2001). Consistent with these findings, our study pro- vides clear evidence in vivo that HIF-1 $\alpha$ is essential for expression of $P G K$ in the growth plate. Furthermore, it suggests that the impairment of $P G K$ up-regulation, and by implication glycolysis generally, has contributed to the massive cell death observed in the growth plate in HIF-1 $1 \alpha^{+\mathrm{f} /-}$; colIIIcre or HIF-1 $\alpha^{+\mathrm{f} / \mathrm{+} \mathrm{f}}$; colIIIcre null animals through a cell-autonomous mechanism. 
Our study also indicates that VEGF mRNA expression in the growth plate is regulated by both HIF-1 $\alpha$ dependent and independent mechanisms. In contrast to what is reported here, animals with impaired VEGF protein expression or activity in the growth plate show no signs of cell death in cartilaginous elements, despite a decreased number of blood vessels in the surrounding primary spongiosa (Gerber et al. 1999; Haigh et al. 2000). Furthermore, data from $M M P 9$ null mutant mice indicate that angiogenic factor release is critical for the remodeling of the hypertrophic zones, but has no role in survival of chondrocytes in the growth plate generally (Vu et al. 1998). Together, these data suggest that decreased levels of VEGF are not the sole cause of the centralized and internal cell death observed in the growth plate of $H I F-1 \alpha^{+\mathrm{f} /-}$; colIIcre or HIF-1 $\alpha^{+\mathrm{f} /+\mathrm{f}}$; colIIcre null animals. Consistent with this notion, we did not observe changes in blood vessel morphology or density in the vicinity of the chondrosternal junctions of the ribs, in which no primary spongiosa ever forms, despite the occurrence in these areas of a dramatic and centralized cell death.

It is still an open question whether HIF- $1 \alpha$, in addition to modulating cellular metabolism and VEGF expression, also has an effect on cell proliferation and differentiation. It has been reported that genes involved in controlling cell cycle exit are up-regulated by hypoxia through HIF-1 $\alpha$ dependent mechanisms (Carmeliet et al. 1998). Conversely, stimuli such as insulin, insulin-like growth factors 1 and 2, EGF, and PDGF have also been shown to increase HIF- $1 \alpha$ protein levels in a cell-specific manner (Zelzer et al. 1998; Richard et al. 1999). In this paper, we report the intriguing and novel finding that the lack of HIF-1 $\alpha$ not only causes chondrocyte death in the central portion of the cartilaginous elements, but also increases the DNA synthesis rate at the periphery of the growth plate. It also decreases expression of $p 57$, an effector of chondrocytic growth arrest, and creates a subtle delay in the process of hypertrophic differentiation. Whether these effects on DNA synthesis and differentiation are cell-autonomous and caused directly by the lack of HIF- $1 \alpha$ transcriptional activity, or secondary to the dramatic changes in the redox status of the cells surrounding the areas of cell death or changes in the vascularization of the growth plate, are questions that need to be investigated.

It is likely that the dramatic shortening of the limbs observed in the null mice is the end result of diverse and numerous effects, such as severe cell death, subtle delays of the hypertrophic differentiation process, and the disorganized transition from hypertrophic chondrocytes to primary spongiosa. These various processes impinge on all of the areas of cartilaginous growth we evaluated, including a very critical one: We have shown that the likely mode of death of these mice comes from defects in the trachea, which shows signs of collapse when HIF- $1 \alpha$ is absent from the cartilaginous rings.

In summary, we have shown that there is a physiological gradient of oxygenation in the cartilaginous growth plate, and that this is correlated with HIF-1 $\alpha$ expression in chondrocytes. We have shown that HIF-1 $\alpha$ activity is essential for the survival of hypoxic cells in this avascular tissue. This has important implications for the survival of tissues that lack even transiently a functional vasculature, and implies that HIF- $1 \alpha$ may be a critical target for modulating hypoxic cell survival. Furthermore, we have provided evidence that VEGF expression in the growth plate is regulated through HIF- $1 \alpha$-dependent and -independent mechanisms. Lastly, we report that HIF- $1 \alpha$ is not only crucial for survival of hypoxic chondrocytes, but also modulates the process of chondrocyte proliferation, differentiation, and growth arrest.

This is the first in vivo model that demonstrates the physiological role of HIF- $1 \alpha$ in cellular adaptation to hypoxia during fetal development; as such, it points out the essential role microphysiological response plays in mammalian ontogeny, and illustrates the complexity of HIF- $1 \alpha$ action in vivo.

\section{Materials and methods}

Generation of Cre transgenic lines and conditional HIF-1 $\alpha$ knockout

A 1.7-kb DNA fragment containing a nuclear localization signal (NLS), the cDNA encoding the bacterial Cre recombinase, and a polyadenylation signal, was excised from pOG44 vector (Stratagene) by SmaI/KpnI digestion. It was blunted, ligated to BgIII linkers, and then digested with BgIII. The BgIII fragment was ligated to a BamHI site in the p1757 plasmid, kindly provided by Dr. Y. Yamada (National Institute of Dental Research, National Institutes of Health, Bethesda, MD) (Yamada et al. 1990). The p1757 plasmid had been modified previously by substitution of the AfIIII site with an EcoRI site. As a result of this cloning strategy, the cDNA encoding the Cre recombinase was located down-stream of the rat collagen $2 a 1$ promoter element (-977 to +110 ), between a 640 -bp fragment containing a rabbit $\beta$-globin intronic sequence and an enhancer element specific for chondrocytes. Nucleotide sequence analysis confirmed the correct orientation of the cDNA, the presence of an in frame stop codon and of the native Kozak consensus sequence up-stream of the translation initiation codon. The construct insert was released from the vector by digestion with EcoRI, and was microinjected into fertilized eggs from $\mathrm{FVB} / \mathrm{N}$ females. The injected eggs were then transferred to pseudopregnant female mice. Genomic DNA extracted from tail biopsies by standard techniques, it was digested with BamHI, and the subsequent Southern blot was probed with a ${ }^{32} \mathrm{P}$-labeled 380 -bp fragment from the cDNA encoding Cre recombinase. The BamHI digestion of mouse genomic DNA containing the transgene yields one hybridizing DNA species of $\sim 4 \mathrm{~kb}$ (data not shown).

$\mathrm{F}_{1}$ Cre offspring (collIcre) from both transgenic lines were bred with animals that were heterozygous for a HIF-1 $\alpha^{+f}$ allele created by knock-in mutation and for the HIF-1 $\alpha^{-}$null allele, respectively (Ryan et al. 1998, 2000). After appropriate breeding, both HIF-1 $\alpha^{+\mathrm{f} /-}$; collIcre and HIF-1 $\alpha^{+\mathrm{f} /+\mathrm{f}}$; colIIcre mutant mice were generated. PCR was performed to identify the $\operatorname{lox} P$ site on the 3 '-end side of exon 2, by using the forward primer HF 26 (5'-TGATGTCCCTGCTGGTGTC-3') and the reverse primer HF 27 (5'-TTGTGTTGGGGCAGTACTG-3') (wild-type allele $312 \mathrm{bp}$, mutant allele $350 \mathrm{bp}$ ). PCR was also performed to identify the presence of the neomycin gene in the HIF-1 $\alpha$ null allele by using the primers 5'-AAGGTGAGATGACAGGAGATC-3', 
and 5'-GATCGGCCATTGAACAAGATG-3', respectively (310bp PCR product).

Analysis of EF-5 distribution; whole-mount $\beta$-galactosidase and Alizarin Red S stainings

To study EF-5 distribution, pregnant females were injected with $10 \mathrm{mM}$ EF5 at $1 \%$ of body weight; staining was performed as described previously (Ryan et al. 1998, 2000).

Whole-mount lacZ staining was performed as described previously (Ryan et al. 1998).

Histological analysis, in situ hybridization analysis, and TUNEL assay

For light microscopy, tissues from E14.5, E15.5, E17.5, and E18.5 (delivered by caesarean section), and newborn were fixed in $10 \%$ formalin/PBS ( $\mathrm{pH} 7.4)$, and stored in fixative at $4{ }^{\circ} \mathrm{C}$. Paraffin blocks were prepared by standard histological procedures. Sections (5-6 $\mu \mathrm{m}$ thickness) were cut from several levels of the block, and stained with Hematoxylin $(\mathrm{H})$ and Eosin $(\mathrm{E})$. Selected samples were quickly fresh frozen in OCT on dry ice, and sections $(10 \mu \mathrm{m})$ were subsequently cut. In situ hybridizations were performed using complementary ${ }^{35}$ S-labeled riboprobes as described previously (Lee et al. 1996b).

For TUNEL assay, paraffin sections from hindlimbs of newborn mice were permeabilized with $0.1 \%$ Triton X-100 in $0.1 \%$ sodium citrate. TUNEL assay was performed using a Roche In situ cell death detection Kit (Roche, Germany), according to the manufacturer's conditions.

\section{BrdU incorporation}

E15.5 and E14.5 pregnant mice were injected intraperitoneally with $100 \mu \mathrm{g}$ of BrdU/12 $\mu \mathrm{g}$ of FdU per gram body weight $2 \mathrm{~h}$ prior to sacrifice. After sacrifice, embryo hindlimbs were dissected, fixed, and embedded in paraffin, and longitudinal sections across the tibia and femur were obtained. To identify actively proliferating cells, nuclei that had incorporated BrdU were detected using a Zymed BrdU immunostaining kit (Zymed Laboratories).

\section{Immunohistochemistry}

For HIF- $1 \alpha$ detection, fresh frozen sections from E15.5 wild-type embryos were fixed in acetone for $20 \mathrm{~min}$ at $-20^{\circ} \mathrm{C}$ and then permeabilized with $0.1 \%$ Triton X-100 in $0.1 \%$ sodium citrate. After blocking, sections were incubated with the commercially available antibody C-19 that specifically recognizes an epitope in the C-terminal portion of the HIF $1 \alpha$ protein (Santa Cruz Biotech), at a dilution of 1:100. Detection of the binding was carried by the Streptdavidin-HRP system provided by TSA kit, according to the manufacturer's conditions.

Forvon Willebrand factor detection, paraffin sections of newborn mice were heated at $80^{\circ} \mathrm{C}$ in $0.1 \mathrm{M}$ citrate buffer $(\mathrm{pH}$ 6.0) for $2 \mathrm{~h}$. After blocking, sections were incubated with a commercially available rabbit polyclonal antibody that recognizes the mouse von Willebrand factor (Dako), at a dilution of 1:100 for 1 $\mathrm{h}$ at room temperature. Detection of the binding was carried out as described above.

\section{Acknowledgments}

We are grateful to Dr. H.M. Kronenberg for helpful discussions and critical review of the manuscript, as well as Drs. H. Mac-
Lean, A. Giaccia, J. Arbeit, T. Seagroves, T. Cramer, N. Goda, M. Kim, A. Dadak, S.-K. Park, and G.-C. Li, for helpful discussions. We are also grateful to Wayne McNulty and Bahram Khadivi for excellent technical assistance. This work was supported in part by NIH grants AR44855 and CA82515.

The publication costs of this article were defrayed in part by payment of page charges. This article must therefore be hereby marked "advertisement" in accordance with 18 USC section 1734 solely to indicate this fact.

\section{References}

Carmeliet, P., Dor, Y., Herbert, J.M., Fukumura, D., Brusselmans, K., Dewerchin, M., Neeman, M., Bono, F., Abramovitch, R., Maxwell, P., et al. 1998. Role of HIF-1 $\alpha$ in hypoxiamediated apoptosis, cell proliferation and tumour angiogenesis. Nature 394: 485-490.

Elson, D.A., Ryan, H.E., Snow, J.W., Johnson, R., and Arbeit, J.M. 2000. Coordinate up-regulation of hypoxia inducible factor (HIF)- $1 \alpha$ and HIF-1 target genes during multi-stage epidermal carcinogenesis and wound healing. Cancer Res. 60: 6189-6195.

Erlebacher, A., Filvaroff, E.H., Gitelman, S.E., and Derynck. R. 1995. Toward a molecular understanding of skeletal development. Cell 80: 371-378.

Firth, J.D., Ebert, B.L., Pugh, C.W., and Ratcliffe, P.J. 1994. Oxygen-regulated control elements in the phosphoglycerate kinase 1 and lactate dehydrogenase A genes: Similarities with the erythropoietin $3^{\prime}$ enhancer. Proc. Natl. Acad. Sci. 91: 6496-6500.

Gerber, H., Vu, T., Ryan, A., Kowalski, J., Werb, Z., and Ferrara, N. 1999. VEGF couples hypertrophic cartilage remodeling, ossification and angiogenesis during endochondral bone formation. Nat. Med. 5: 623-628.

Haigh, J., Gerber, H., Ferrara, N., and Wagner, E. 2000. Conditional inactivation of VEGF-A in areas of collagen2a1 expression results in embryonic lethality in the heterozygous state. Development 127: 1445-1453.

Harper, J. and Klagsbrun, M. 1999. Cartilage to bone-Angiogenesis leads the way. Nat. Med. 5: 617-618.

Harvey, E.N. 1928. The oxygen consumption of luminous bacteria. J. Gen. Physiol. 11: 469-475.

Iyer, N.V., Kotch, L.E., Agani, F., Leung, S.W., Laughner, E., Wenger, R.H., Gassmann, M., Gearhart, J.D., Lawler, A.M., Yu, A.Y., et al. 1998. Cellular and developmental control of $\mathrm{O}_{2}$ homeostasis by hypoxia-inducible factor 1 alpha. Genes \& Dev. 12: 149-162.

Jain, S., Maltepe, E., Lu, M.M., Simon, C., and Bradfield, C.A. 1998. Expression of ARNT, ARNT2, HIF $1 \alpha$, HIF $2 \alpha$ and Ah receptor mRNAs in the developing mouse. Mech. Dev. 73: 117-123.

Kung, A.L., Wang, S., Klco, J.M., Kaelin, W.G., and Livingston, D.M. 2000. Suppression of tumor growth through disruption of hypoxia-inducible transcription. Nat. Med. 6: 1335-1340.

Lee, J., Siemann, D., Koch, C., and Lord, E. 1996a. Direct relationship between radiobiological hypoxia in tumors and monoclonal antibody detection of EF5 cellular adducts. Int. J. Cancer 67: 372-378.

Lee, K., Lanske, B., Karaplis, A., Deeds, J., Kohno, H., Nissenson, R., Kronenberg, H., and Segre, G. 1996b. Parathyroid hormone-related peptide delays terminal differentiation of chondrocytes during endochondral bone development. Endocrinology 137: 5109-5118.

Li, H., Ko, H.P., and Whitlock, J.P. 1996. Induction of phosphoglycerate kinase 1 gene expression by hypoxia. Roles of Arnt 
Schipani et al.

and HIF1 $\alpha$. J. Biol. Chem. 271: 21262-21267.

Lord, E., Harwell, L., and Koch, C. 1993. Detection of hypoxic cells by monoclonal antibody recognizing 2-nitroimidazole adducts. Cancer Res. 53: 5721-5726.

Maxwell, P., Dachs, G., Gleadle, J., Nicholls, L., Harris, A., Stratford, I., Hankinson, O., Pugh, C., and Ratcliffe, P. 1997. Hypoxia-inducible factor 1 modulates gene expression in solid tumors and influences both angiogenesis and tumor growth. Proc. Natl. Acad. Sci. 94: 8104-8109.

Nagahama, H., Hatakeyama, S., Nakayama, K., Nagata, M., and Tomita, K. 2001. Spatial and temporal expression patterns of the cyclin-dependent kinase (CDK) inhibitors p27Kip1 and p57Kip2 during mouse development. Anat. Embryol. 203: 77-87.

Rajpurohit, R., Koch, C.J., Tao, Z., Teixeira, C.M., and Shapiro, I.M. 1996. Adaptation of chondrocytes to low oxygen tension: Relationship between hypoxia and cellular metabolism. J. Cell Physiol. 168: 424-432.

Ratcliffe, P., Pugh, C., and Maxwell, P. 2000. Targeting tumors through the HIF system. Nat. Med. 12: 1315-1316.

Richard, D.E., Berra, E., and Pouysségur, J. 1999. Angiogenesis: How a tumor adapts to hypoxia. Biochem. Biophys. Res. Commun. 266: 718-722.

Ryan, H.E., Lo, J., and Johnson, R.S. 1998. HIF- $1 \alpha$ is required for solid tumor formation and embryonic vascularization. EMBO J. 17: 3005-3015.

Ryan, H.E., Poloni, M., McNulty, W., Elson, D., Gassmann, M., Arbeit, J.M., and Johnson, R.S. 2000. Hypoxia-inducible factor- 1 alpha is a positive factor in solid tumor growth. Cancer Res. 60: 4010-4015.

Schmidt-Nielsen, K. 1990. Animal physiology Cambridge University Press, Cambridge, UK.

Seagroves, T.N., Ryan, H.E., Lu, H., Wouters, B.G., Knapp, M., Thibault, P., Laderoute, K., and Johnson, R.S. 2001. Transcription factor HIF-1 is a necessary mediator of the pasteur effect in mammalian cells. Mol. Cell. Biol. 21: 3436-3444.

Semenza, G. 1999. Regulation of mammalian $\mathrm{O}_{2}$ homeostasis by hypoxia-inducible factor 1. Annu. Rev. Cell. Dev. Biol. 15: 551-578.

-2000a. Expression of hypoxia-inducible factor 1: Mechanisms and consequences. Biochem. Pharmacol. 59: 47-53.

- 2000b. Hypoxia, clonal selection, and the role of HIF-1 in tumor progression. Crt. Rev. Biochem. Mol. Biol. 35: 71103.

Semenza, G.L., Roth, P.H., Fang, H.M., and Wang, G.L. 1994. Transcriptional regulation of genes encoding glycolytic enzymes by hypoxia-inducible factor 1. J. Biol. Chem. 269: 23757-23763.

Soriano, P. 1999. Generalized lacZ expression with the ROSA26 Cre reporter strain. Nat. Genet. 21: 70-71.

Vu, T.H., Shipley, J.M., Bergers, G., Berger, J.E., Helms, J.A., Hanahan, D., Shapiro, S.D., Senior, R.M., and Werb, Z. 1998. MMP-9/gelatinase B is a key regulator of growth plate angiogenesis and apoptosis of hypertrophic chondrocytes. Cell 93: 411-422.

Weiner, C.M., Booth, G., and Semenza, G.L. 1996. In vivo expression of mRNAs encoding hypoxia-inducible factor 1 . Biochem. Biophys. Res. Commun. 225: 485-488.

Wood, S.M., Wiesener, M.S., Yeates, K.M., Okada, N., Pugh, C.W., Maxwell, P.H., and Ratcliffe, P.J. 1998. Selection and analysis of a mutant cell line defective in the hypoxia-inducible factor-1 alpha subunit (HIF-1 $\alpha)$. J. Biol. Chem. 273: 8360-8368.

Yamada, Y., Miyashita, T., Savagner, P., Horton, W., Brown, K.S., Abramczuk, J., Xie, H.X., Kohno, K., Bolander, M., and Bruggeman, L. 1990. Regulation of the collagen II gene in vitro and in transgenic mice. Ann. NY Acad. Sci. 580: 81-87.

Yan, Y., Frisén, J., Lee, M.H., Massagué, J., and Barbacid, M. 1997. Ablation of the CDK inhibitor p57Kip2 results in increased apoptosis and delayed differentiation during mouse development. Genes \& Dev. 11: 973-983.

Zelzer, E., Levy, Y., Kahana, C., Shilo, B.Z., Rubinstein, M., and Cohen, B. 1998. Insulin induces transcription of target genes through the hypoxia-inducible factor HIF-1 $\alpha /$ ARNT. EMBO J. 17: 5085-5094.

Zhang, P., Liégeois, N.J., Wong, C., Finegold, M., Hou, H., Thompson, J.C., Silverman, A., Harper, J.W., DePinho, R.A., and Elledge, S.J. 1997. Altered cell differentiation and proliferation in mice lacking p57KIP2 indicates a role in Beckwith-Wiedemann syndrome. Nature 387: 151-158.

Zhong, H., Chiles, K., Feldser, D., Laughner, E., Hanrahan, C., Georgescu, M.M., Simons, J.W., and Semenza, G.L. 2000. Modulation of hypoxia-inducible factor $1 \alpha$ expression by the epidermal growth factor/phosphatidylinositol 3-kinase/ PTEN/AKT/FRAP pathway in human prostate cancer cells: Implications for tumor angiogenesis and therapeutics. Cancer Res. 60: 1541-1545.

Zundel, W., Schindler, C., Haas-Kogan, D., Koong, A.,. Kaper, F, Chen, E., Gottschalk, A.R., Ryan, H.E., Johnson, R.S., Jefferson, A.B., et al. 2000. Loss of PTEN facilitates HIF-1-mediated gene expression. Genes \& Dev. 14: 391-396. 


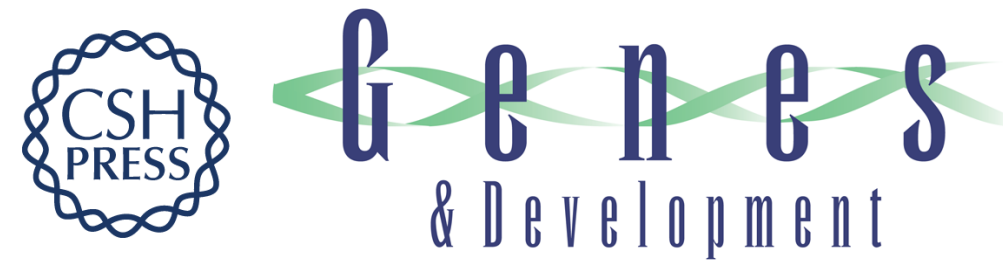

\section{Hypoxia in cartilage: HIF-1 $\alpha$ is essential for chondrocyte growth arrest and survival}

Ernestina Schipani, Heather E. Ryan, Susanna Didrickson, et al.

Genes Dev. 2001, 15:

Access the most recent version at doi:10.1101/gad.934301

References

This article cites 36 articles, 17 of which can be accessed free at: http://genesdev.cshlp.org/content/15/21/2865.full.html\#ref-list-1

\section{License}

Email Alerting

Receive free email alerts when new articles cite this article - sign up in the box at the top Service right corner of the article or click here.

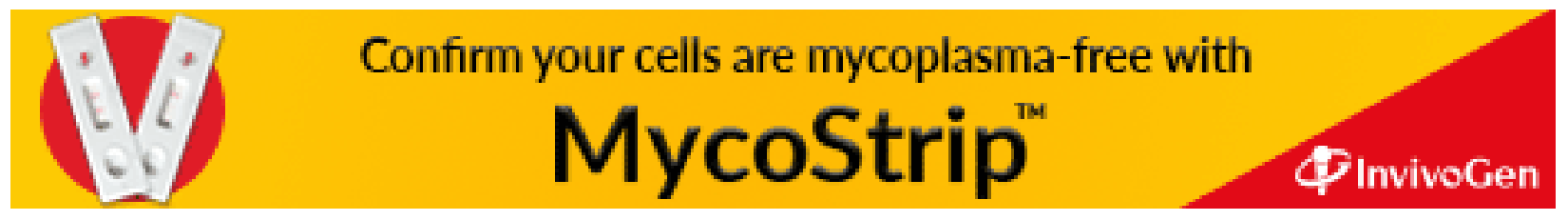

